\title{
Complex permittivity, permeability and microwave absorbing properties of Co-Ti substituted strontium hexaferrite
}

\author{
SukHleEn Bindra NARANG, PAwANdeEP KauR*, Shalini BAhel \\ Guru Nanak Dev University, Amritsar, Punjab, India
}

\begin{abstract}
M-type strontium ferrite with compositions $\mathrm{SrFe}_{(12-2 \mathrm{x})} \mathrm{Co}_{\mathrm{x}} \mathrm{Ti}_{\mathrm{x}} \mathrm{O}_{19}(\mathrm{x}=0.0,0.3,0.5,0.7,1.0)$, were prepared by two route ceramic method. The effects of Co-Ti substitution on their microstructure, electromagnetic properties, and microwave absorptive behavior were analyzed. The complex permittivity $\left(\varepsilon^{\prime}-\mathrm{j} \varepsilon^{\prime \prime}\right)$ and complex permeability $\left(\mu^{\prime}-\mathrm{j} \mu^{\prime \prime}\right)$ have been measured from 8.2 to $12.4 \mathrm{GHz}$ using a network analyzer. Scanning electron microscope was used to analyze the grain size distribution and porosity of the ferrite. X-ray diffraction confirmed the M-type structure of the doped strontium ferrite. Vibrating sample magnetometer was used to study hysteresis loop of the ferrite. This study suggests that the control of grain size, decrease in coercivity and enhanced values of dielectric constant and loss are effective means to improve microwave absorption. The dielectric constant and loss were enhanced in comparison to the permeability constant and loss over the entire frequency range.
\end{abstract}

Keywords: dielectric properties; hexaferrites; magnetic properties

(C) Wroclaw University of Technology.

\section{Introduction}

The rapid development of gigahertz $(\mathrm{GHz})$ frequency telecommunications and electronically controlled systems has resulted in a growing trend in research of materials that can be used as electromagnetic absorbers. Electromagnetic interference (EMI) can cause electronic device malfunctions, generate glitches and reduce the performance of the system. Strontium and barium hexagonal ferrites are the most important ceramic materials that have been used extensively as microwave absorbers to reduce EMI and an electromagnetic compatibility (EMC) problem. In this field, many efforts have been reported on M-type hexagonal ferrites for their use as electromagnetic materials [1-5].

Electric and magnetic energy storage capabilities of a material are represented by real parts of complex permittivity $\left(\varepsilon^{\prime}\right)$ and permeability $\left(\mu^{\prime}\right)$. The imaginary parts $\left(\varepsilon^{\prime \prime}, \mu^{\prime \prime}\right)$ represent the loss of electric and magnetic energy. Two fundamental conditions must be satisfied for a good reflecting absorber material: the first is that the incident

*E-mail: pawandeep.baria@gmail.com wave could enter the absorber to the greatest extent, and the second is that the electromagnetic wave entering into the materials could be entirely attenuated $[6,7]$.

Here, we have reported the detailed analysis of electromagnetic properties and microwave absorption of the hexaferrites, $\mathrm{SrFe}_{(12-2 \mathrm{x})} \mathrm{Co}_{\mathrm{x}} \mathrm{Ti}_{\mathrm{x}} \mathrm{O}_{19}$ (where $\mathrm{x}=0.0,0.3,0.5,0.7,1.0$ ), and tried to illustrate the effect of the Co-Ti substitution for $\mathrm{Fe}^{3+}$ on these properties. The synthesized hexaferrites were characterized by X-ray powder diffraction (XRD), scanning electron microscope (SEM), vibrating sample magnetometer (VSM) and vector network analyzer (VNA).

\section{Experimental}

M-type hexagonal ferrites with compositions $\mathrm{SrFe}_{(12-2 \mathrm{x})} \mathrm{Co}_{\mathrm{x}} \mathrm{Ti}_{\mathrm{x}} \mathrm{O}_{19}(\mathrm{x}=0.0,0.3,0.5,0.7,1.0)$, were synthesized by the conventional ceramic processing method. The detailed procedure of the synthesis has been published in our previous paper [8]. The pellets were sintered in air at a temperature of $1300{ }^{\circ} \mathrm{C}$ for 12 hours in an electric furnace. Then the pellets were shaped to fit exactly into a $10.16 \times 22.86 \mathrm{~mm}^{2}$ rectangular X-band waveguide 
(WR-90). The complex scattering parameters that correspond to the reflection $\left(\mathrm{S}_{11}\right.$ or $\left.\mathrm{S}_{22}\right)$ and transmission $\left(S_{21}\right.$ or $\left.S_{22}\right)$ were measured using a vector network analyzer (Agilent N5225A PNA series). Full two-port calibration was initially done on the test setup in order to remove errors due to source/load match, isolation etc. The complex permittivity $\left(\varepsilon^{\prime}-\mathrm{j} \varepsilon^{\prime \prime}\right)$ and permeability $\left(\mu^{\prime}-\mathrm{j} \mu^{\prime \prime}\right)$ were then determined from the measured scattering parameters using Agilent software module 85071 in the frequency range of 8.2 to $12.4 \mathrm{GHz}$ at room temperature. From these electromagnetic parameters, the reflection loss (RL) was calculated and microwave absorbing properties were determined. Magnetic measurements were performed by using a vibrating sample magnetometer (Microsense) and magnetization measurements were carried out in an external field up to $17 \mathrm{kOe}$ at room temperature. The phase structure was characterized using $\mathrm{X}$-ray diffraction (D8 Bruker) with $\mathrm{CuK} \alpha$ radiation $(\lambda=1.54 \AA)$ and microstructure was studied with SEM instrument (Zeiss-Supra 55).

\section{Results and discussion}

The frequency dependence of $\varepsilon^{\prime}, \varepsilon^{\prime \prime}, \mu^{\prime}$ and $\mu^{\prime \prime}$, for Co-Ti doped strontium ferrite at $\mathrm{x}=0.0$, $0.3,0.5,0.7,1.0$ are shown in Fig. 1. It is clearly visible in Fig. 1a that dielectric constant $\left(\varepsilon^{\prime}\right)$ of all the samples have increased with substitution as compared to $\mathrm{x}=0.0$ except the sample with the composition $x=0.7$. The variation of dielectric constant with frequency reveals the dispersion of Maxwell-Wagner-type [9-12]. According to Koop's theory which is in agreement with Maxwell-Wagner's model, the dielectric materials with non-homogenous structure can be imagined to contain well-conducting grains separated by poor conducting grain boundaries. The grain boundaries of lower conductivity were found to be effective at lower frequencies, while ferrite grain boundaries of high conductivity are effective at higher frequencies [13]. With an increase in substitution of Co-Ti ions in strontium ferrite more $\mathrm{Fe}^{3+}$ ions transform to $\mathrm{Fe}^{2+}$ ions. The $\mathrm{Fe}^{2+}$ ions result in the polarization on the sample surface, causing the increase of dielectric constant $\left(\varepsilon^{\prime}\right)[14]$.
From Fig. 1b, it is seen that $\varepsilon^{\prime \prime}$ also exhibits a higher value with substitution as compared to $\mathrm{x}=0.0$ the sample for all the samples except $\mathrm{x}=0.7$ which exhibits a decrease in $\varepsilon^{\prime \prime}$ at the frequencies lower than $9.8 \mathrm{GHz}$. The decrease in values of $\varepsilon^{\prime}$ and $\varepsilon^{\prime \prime}$ at $\mathrm{x}=0.7$ sample is attributed to the decrease of eddy-current loss which is connected with high resistivity of the ferrite. It is known that lattice distortion occurs with an excess of substitution content, which results in an increase of electron scattering and resistivity of ferrite [15].

Low $\mu^{\prime}$ and $\mu^{\prime \prime}$ are observed in all the samples in comparison to $\varepsilon^{\prime}$ and $\varepsilon^{\prime \prime}$, along entire frequency range. It is clearly visible in Fig. 1d that imaginary parts of permeability $\left(\mu^{\prime \prime}\right)$ have decreased with substitution for all the samples as compared to $\mathrm{x}=0.0$. In Fig. 1c and Fig. 1d, a resonance peak is observed for $\mathrm{x}=0.7$ sample in the real and imaginary part of permeability with maximum values of 1.758 at $11.81 \mathrm{GHz}$ and 0.4368 at $11.89 \mathrm{GHz}$, respectively. The hysteresis loops of the as synthesized strontium ferrites are shown in Fig. 2. In M-type hexagonal ferrite, $\mathrm{Fe}^{3+}$ ions occupy seven octahedral sites $12 \mathrm{k}$ and $2 \mathrm{a}$, trigonal sites $2 \mathrm{~b}$ with spins in one direction, two octahedral sites $4 \mathrm{fI}$ and two tetrahedral sites 4fII with spins in opposite direction [16]. Magnetization increases with substitution of Co-Ti ions at $\mathrm{x}=0.3,0.5,0.7$, 1.0 in comparison with $\mathrm{x}=0.0(45.36 \mathrm{emu} / \mathrm{gm})$ sample. Magnetization increases by $30.7 \%$ from $\mathrm{x}=0.0$ to $\mathrm{x}=0.5$ sample. This can be ascribed to replacement of $\mathrm{Fe}^{3+}$ ions in spin down state by Co-Ti. Reduction of magnetization by $35.4 \%$ occurs from $x=0.5$ to $x=0.7$ (Fig. 3). This can be ascribed to the magnetic moments of both ions which are not able to cancel out with spin down moments of $\mathrm{Fe}^{3+}$ ions $\left(5 \mu_{\mathrm{B}}\right)$ owing to the weak magnetic nature of $\mathrm{Co}^{2+}$ ions $\left(3 \mu_{\mathrm{B}}\right)$ and $\mathrm{Ti}^{4+}$ ions $\left(0 \mu_{B}\right)[17]$.

Overall coercivity $(\mathrm{Hc})$ decreases with an increase in substitution in strontium ferrite from $\mathrm{x}=0.1$ to $\mathrm{x}=1.0$. Fast reduction by $65 \%$ of Hc occurs from the sample $\mathrm{x}=0.0(3037 \mathrm{Oe})$ to $\mathrm{x}=0.5$ $(1054 \mathrm{Oe})$ and by $72.4 \%$ from $\mathrm{x}=0.0$ to $\mathrm{x}=1.0$ (837 Oe). Coercivity also decreased by $85 \%$ in $\mathrm{Ba}-\mathrm{Sr}-\mathrm{Co}-\mathrm{Zr}$ ferrite [18]. In general, the result 

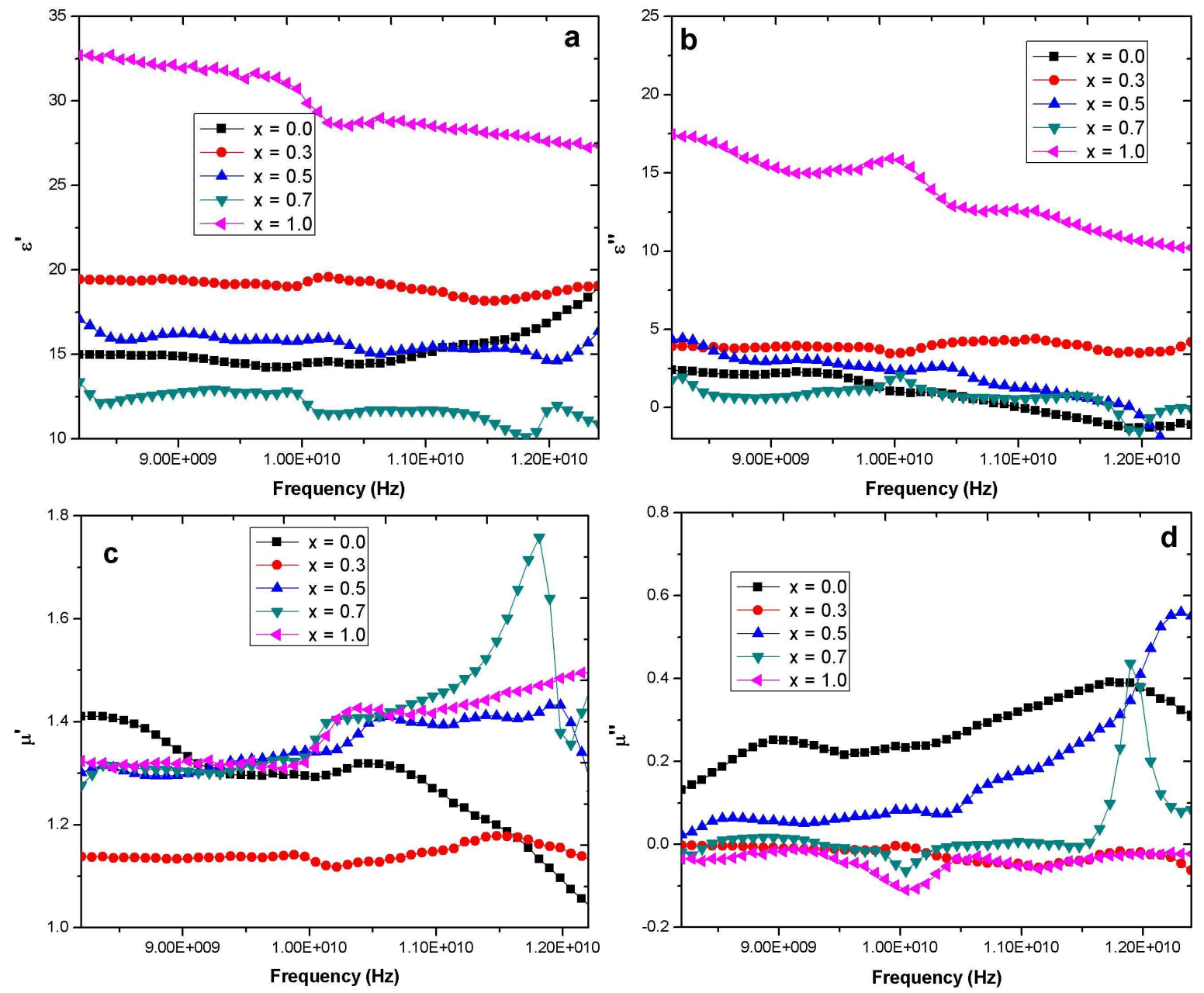

Fig. 1. (a) $\varepsilon^{\prime}$, (b) $\varepsilon^{\prime \prime}$, (c) $\mu^{\prime}$, and (d) $\mu^{\prime \prime}$ variations with frequency in $\operatorname{Sr}(\mathrm{CoTi})_{\mathrm{x}} \mathrm{Fe}_{(12-2 \mathrm{x})} \mathrm{O}_{19}$.
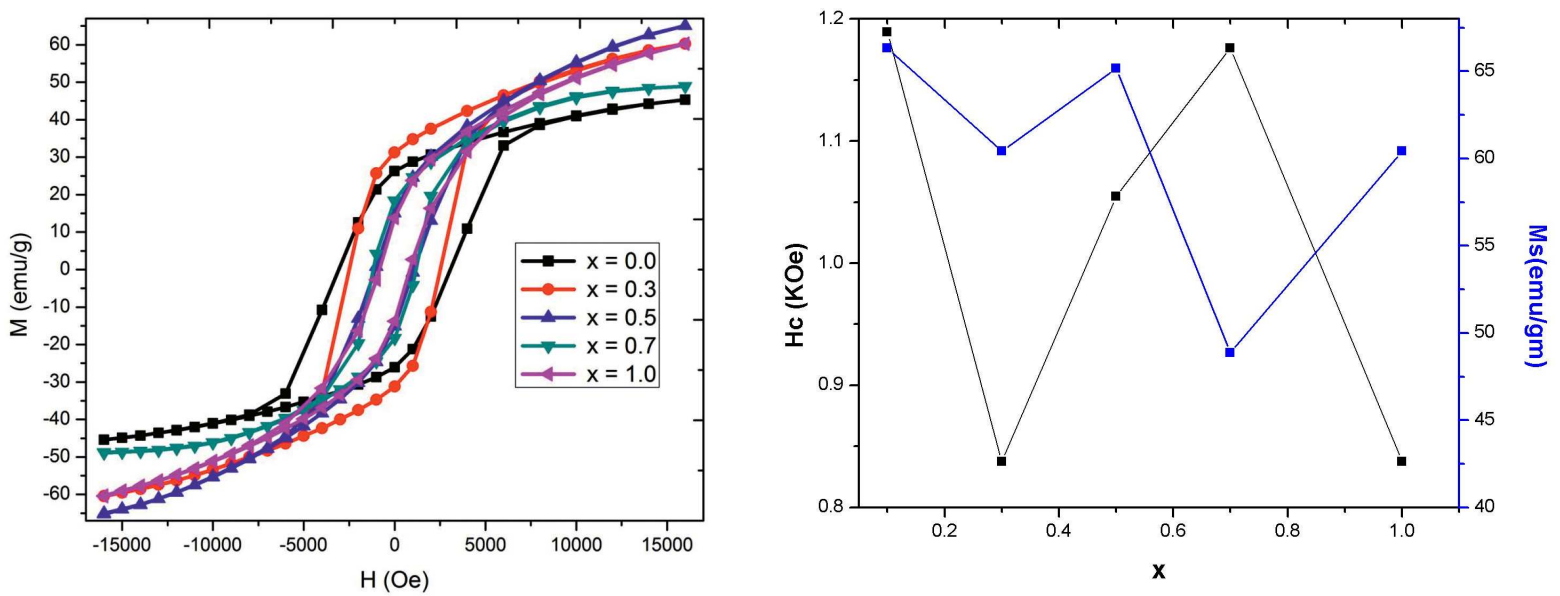

Fig. 2. Magnetization versus applied field for $\mathrm{Sr}$ Fig. 3. Coercivity (Hc) and magnetization (M) for the $(\mathrm{CoTi})_{\mathrm{x}} \mathrm{Fe}_{(12-2 \mathrm{x})} \mathrm{O}_{19}$. data taken from M-H curves in Fig. 2. 
shows that substitution leads to a decrease in Hc through the reduction of magnetocrystalline anisotropy in strontium ferrite. It is observed that the $\mathrm{x}=0.0$ sample possesses the largest coercive force and the largest hysteresis loop area. On the other hand, Co-Ti substitution led to a rapid decrease in Hc. The hard pure ferrite becomes the softer the more $\mathrm{Fe}^{3+}$ ions are substituted by $\mathrm{Co}-\mathrm{Ti}$ ions. The result is attributed to the reduction in the crystal anisotropy field, due to the change in the easy-axis of magnetization from c-axis to basal plane [19]. The moderately low Hc indicates that the sample is a soft magnetic material and the domain wall motion is the dominant magnetization mechanism. It should be noted that the reduction in coercive force is authenticated by the fact that it is inversely related to grain size [20].

Fig. 4a shows the variation of reflection loss vs. frequency observed in Co-Ti doped strontium ferrite at $\mathrm{x}=0.7$ with a decrease in thickness from 5.0 to $2.2 \mathrm{~mm}$. The bandwidth of pure hexaferrite is too small to be used as a microwave absorber material [21]. Here, $-10 \mathrm{~dB}$ absorbing bandwidth means that the $90 \%$ of reflection loss is achieved and $-20 \mathrm{~dB}$ means that the frequency bandwidth can achieve $99 \%$ of reflection loss. The minimum absorber thickness and the frequency in the matching situation were defined as matching thickness and matching frequency, respectively [22]. It is clearly visible in Fig. 4a that with a decrease in thickness from $5.5 \mathrm{~mm}$ to $2.2 \mathrm{~mm}$, reflection loss peaks are shifted to higher frequency range. This can be explained on the basis of magnetic and dielectric parameters (Fig. 1b and 1d) for the composition $\mathrm{x}=0.7$, where the peaks are shifted to higher frequency side with a decrease in thickness. This is also in agreement with the published paper, where the peak of absorption was shifted towards higher frequency when the sample thickness was reduced [23].

Fig. $4 \mathrm{~b}$ shows the variation of reflection loss vs. frequency observed in $\mathrm{Co}-\mathrm{Ti}$ doped strontium ferrite at $\mathrm{x}=0.0,0.3,0.5,0.7,1.0$ at fixed thickness of $2.6 \mathrm{~mm}$ and also at $\mathrm{x}=0.3,0.5,0.7$ at $5.0 \mathrm{~mm}$. The samples with $\mathrm{x}=0.0,0.3,0.5,0.7$ at the fixed thickness of $2.6 \mathrm{~mm}$ shows minimum

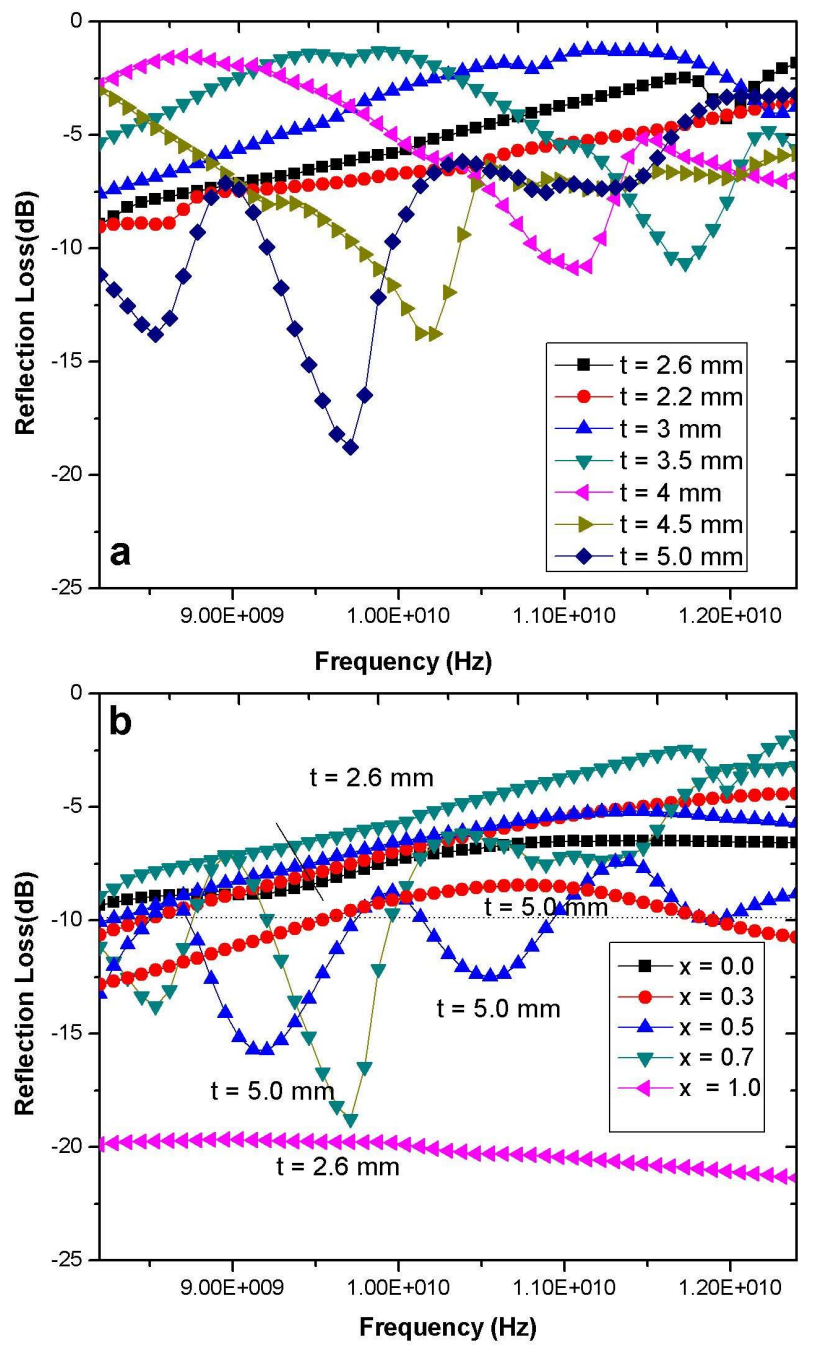

Fig. 4. Reflection loss versus frequency for (a) $\mathrm{Sr}(\mathrm{CoTi})_{0.7} \mathrm{Fe}_{10.6} \mathrm{O}_{19}$ and (b) $\mathrm{Sr}(\mathrm{CoTi})_{\mathrm{X}} \mathrm{Fe}_{(12-2 \mathrm{x})} \mathrm{O}_{19}$.

reflection loss lower than $-10 \mathrm{~dB}$ and does not qualify as a microwave absorber in X-band. According to equation 1 and SEM micrographs, the samples prepared with Co-Ti substitution in this experiment are multi-domain in nature. In case of multi domain particles, there are two peaks in their reflection loss curve versus frequency. The first peak is due to the domain wall motion at lower frequency and the second peak is due to the spin resonance at higher frequency, respectively [24]. As shown in Fig. 4b, minimum RL of $-13 \mathrm{~dB}$ (90\% absorption) at $8.53 \mathrm{GHz}$ for the sample with 


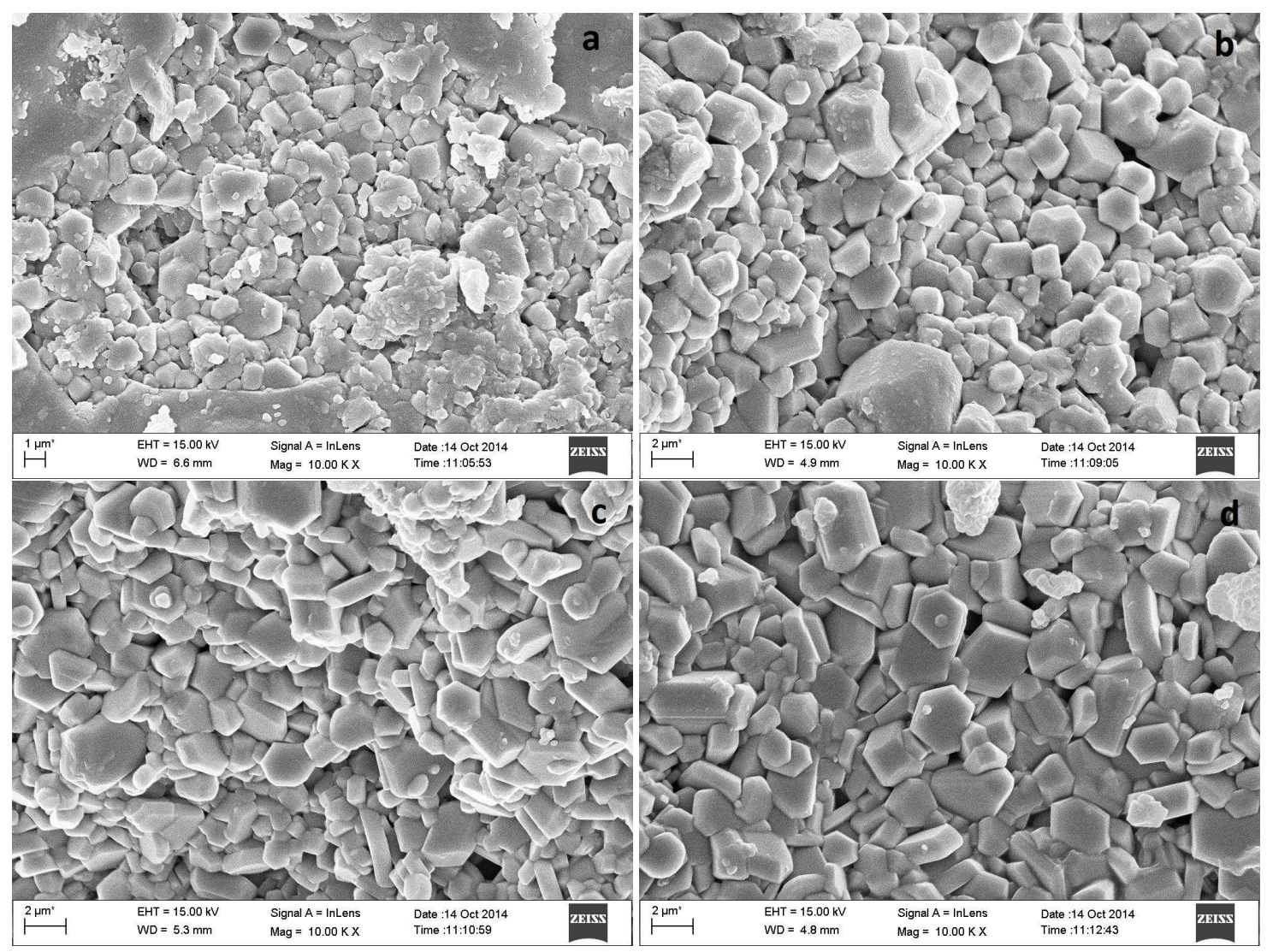

Fig. 5. SEM micrographs of ferrite samples: (a) $\mathrm{SrFe}_{12} \mathrm{O}_{19}$, (b) $\mathrm{Sr}(\mathrm{CoTi})_{0.3} \mathrm{Fe}_{11.4} \mathrm{O}_{19}$, (c) $\mathrm{Sr}(\mathrm{CoTi})_{0.5} \mathrm{Fe}_{11} \mathrm{O}_{19}$, (d) $\mathrm{Sr}(\mathrm{CoTi})_{0.7} \mathrm{Fe}_{10.6} \mathrm{O}_{19}$, (e) $\mathrm{Sr}(\mathrm{CoTi})_{1.0} \mathrm{Fe}_{10} \mathrm{O}_{19}$.

$\mathrm{x}=0.7$ with matching thickness of $5.0 \mathrm{~mm}$ and another peak with minimum RL equal to $-18.77 \mathrm{~dB}$ at $9.71 \mathrm{GHz}$ with absorption bandwidth of 0.8 $\mathrm{GHz}(-10 \mathrm{~dB})$ are observed. The minimum RL of $-15.73 \mathrm{~dB}$ at matching frequency of $9.2 \mathrm{GHz}$ with absorption bandwidth $1.02 \mathrm{GHz}$ for matching thickness $5 \mathrm{~mm}$ for $\mathrm{x}=0.5$ sample and another peak with minimum RL equal to $-12.4 \mathrm{~dB}$ at $10.55 \mathrm{GHz}$ have been achieved. The highest minimum RL, i.e. $-21.3 \mathrm{~dB}$ at matching frequency $12.36 \mathrm{GHz}$ for the thickness of $2.6 \mathrm{~mm}$ has been achieved for $\mathrm{x}=1.0$ sample. It is known that Mtype hexagonal ferrites have high resonance frequency that can be shifted to lower frequency by substitution of Mn-Co-Zr [25]. Finally, it should be noticed that the main absorption mechanism in our samples is due to the dielectric properties.

SEM images (Fig. 5) show hexagonal plateletlike grains of different sizes for the sample $\mathrm{x}=0.3$.

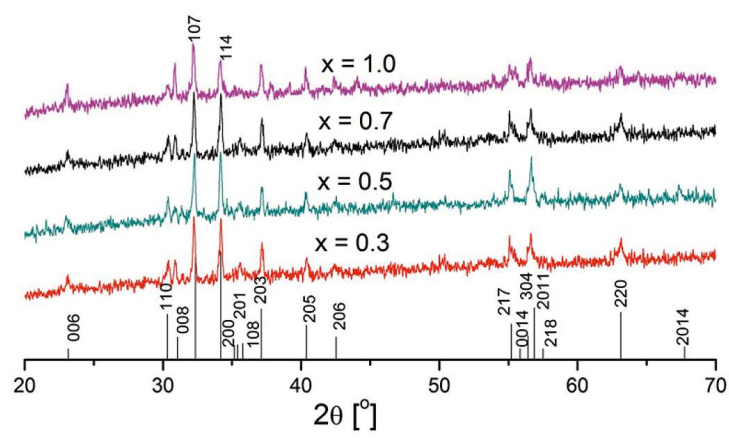

Fig. 6. Indexed X-ray diffraction patterns of strontium ferrites.

The agglomeration of grains takes place with further increase in substitution of Co-Ti ions. In addition, grain boundaries are affected. Average grain size lies in the range of 2 to $3 \mu \mathrm{m}$ for all the samples. These micrographs also indicate a negligible intergranular porosity which is 
the basic requirement for superior quality of ferrite materials. The decrease in calculated porosity matches with observed porosity as revealed in SEM. Domain walls exist when the grain size in the sintered ferrite and the particle size of the magnetic powder becomes larger than critical grain size:

$$
D c=18 u_{0} \sigma_{w} / M s^{2}
$$

where $\sigma_{\mathrm{w}}$ is domain wall energy and Ms is saturation magnetization for the given sample [26].

The prepared in this experiment higher substitution ferrites are multi-domain and there is magnetic loss due to the displacement of domain walls.

$\mathrm{X}$-ray diffraction patterns for samples $\mathrm{x}=0.3$, 0.5, 0.7 and 1.0 are shown in Fig. 6. The change in relative intensities may be related to the occupation of crystallographic sites by Co-Ti substitutional ions. In the doped ferrite samples, the dopants of Co-Ti seem to be rearranged in the hexagonal structure to fulfill the formation of a single hexagonal phase as the main phase (JCPDS Card No. 84-1531). However, some unknown secondary phases appear in X-ray diffraction pattern for the sample $\mathrm{x}=1.0$ (Fig. 6).

\section{Conclusions}

1. This investigation on $\mathrm{Co}-\mathrm{Ti}$ substituted strontium ferrites confirms that microwave attenuation is possible by increasing dielectric losses through choosing an appropriate sintering temperature and substitution, while in previous reports magnetic properties were enhanced to achieve microwave attenuation.

2. Microwave absorbers for applications over 8.5 GHz, with satisfactory reflection loss, could be obtained by controlling the levels of substituted Co-Ti elements in strontium ferrite.

3. Compositions with $\mathrm{x}=0.5$ and $\mathrm{x}=0.7$ are the suitable candidates as microwave absorbers to achieve $90 \%$ microwave attenuation. The absorption in tunable.

\section{References}

[1] Ghasemi A., J. Magn. Magn. Mater., 324 (2012), 1080 .
[2] Singh C., Narang S.B., Hudiara I.S., SudheenDRAN K., RAJU K.C.J., J. Magn. Magn. Mater., 320 (2008), 1657.

[3] QIU J., Gu M., Shen H., J. Magn. Magn. Mater., 295 (2005), 263.

[4] Singh C., Narang S.B., Hudiara I.S., Bai Y., Mater. Lett., 63 (2009), 1921.

[5] Jing W., Hong Z., ShuXin B., KE C., Changrui Z., J. Magn. Magn. Mater., 312 (2007), 310.

[6] Sugimoto S., Haga K., Kagotani T., Inomata K., J. Magn. Magn. Mater., 290 (2005), 1188.

[7] Zhang B.S., Feng Y., XiOng J., YANG Y., LU H.X., IEEE Trans. Magn., 42 (2006), 1778.

[8] Narang S.B., Hudiara I.S., J. Ceram. Process. Res., 7 (2006), 113.

[9] Ni S.B., Wang X.H., Zhou G., YAng F., Wang J.M., HE D.Y., J. Alloy. Compd., 489 (2010), 252.

[10] Singh P., Babbar V.K., Razdan A., PUri R.K., Goel T.C., J. Appl. Phys., 87 (2000), 4362.

[11] MaXwell J.C., Electricity and Magnetism, Oxford University Press, New York, 1973.

[12] Wagner K.W., Amer. Phys., 40 (1973), 817.

[13] Koops C.G., Phys. Rev. 83 (1951), 121.

[14] LiU X.G., Li B., Geng D.Y., Cui W.B., Yang F., Xie Z.G., Kang D.J., Zhang Z.D., Carbon, 47 (2), (2009), 355.

[15] Zhou X.Z., Morrish A.H., Li Z.W., IEEE Trans. Magn., 27 (1991), 4654.

[16] Mendoza-Suarez G., Rivas-VazQuez L.P., Corral-Huacuz J.C., Fuentes A.F., EscalanteGarcia J.I., Physica B, 339 (2003), 110.

[17] FAnG H.C, YANG Z., ONG C.K., Li Y., WANG C.S., J. Magn. Magn. Mater., 187 (1998), 129.

[18] Singh C., Narang S.B., Hudiara I.S., Bai Y., J. Alloy. Compd., 464 (2008), 493.

[19] Dho J., Lee E.K., PArK J.Y., Hur N.H., J. Magn. Mater., 285 (2005), 164.

[20] Kagotani T., Fujiwara D., Sugimoto S., InoMata K., Homma M., J. Magn. Mater., 272 (2004), e1813.

[21] Ghasemi A., Hossienpour A., Morisako A., SaAtchi A., SAlehi M., J. Magn. Magn. Mater, 302 (2006), 429.

[22] Он J.H., OH K.S., Kim C.G., Hong C.S., Composites $B, 35$ (2004), 49.

[23] Menna R.S., Bhattachry A.S., Chatterjee R., J. Magn. Magn. Mater., 322 (2010), 1923.

[24] Ghasemi A., Shirsath S.E., LiU X., Morisako A., J. Appl. Phys., 109 (2011), 07A507.

[25] Ghasemi A., Morisako A., J. Alloy. Compd., 456 (2008), 485.

[26] Singh P., Babbar V.K., Razdan A., Srivastava S.L., PURI R.K., Mater. Sci. Eng. B, 67 (1999), 132. 